\title{
Restrictions on the use of placebo in new COVID-19 vaccine trials
}

\author{
Maurizio Bonati ${ }^{1}$ (])
}

Received: 17 June 2021 / Accepted: 11 August 2021 / Published online: 30 August 2021

(c) The Author(s), under exclusive licence to Springer-Verlag GmbH Germany, part of Springer Nature 2021

Every person has a right to health and to receive medical care with the most appropriate available interventions. This principle of human rights, as enshrined in the Universal Declaration of Human Rights (article 25) [1] and in the World Health Organization Constitution (article 1) [2], is unfortunately still largely unsettled in the world, and wide inequalities in healthcare affect the lives of citizens in all countries. This should, however, be the object of policymakers and professionals' initiatives at the local and international levels.

The large extent of health disparities was further highlighted during the COVID-19 pandemic with the marked differences in how the pandemic was managed around the world.

The urgency to counter the destructive pandemic activated an enormous amount of resources, including public ones, for the rapid production of effective vaccines to prevent symptoms associated with severe acute respiratory coronavirus 2 syndrome (SARS-CoV-2). Quickly, and with incredible results, 8 vaccines received approval for full use by different regulatory agencies around the world [3]. After the emergency designation for vaccines against COVID-19 by a WHO Expert Group [4], it followed the emergency use authorization in the USA, the conditional marketing authorization in the European Union, the approval for use in other countries, and the emergency use list by the WHO. These vaccines have been judged to be effective and safe for use in large populations. This is what has been happening in the world in the past few months with different modalities and intensity in an effort to quickly achieve wide coverage. A few rare adverse events have been reported, but regulatory agencies have concluded that the potential benefits justify the risks in the target population. Global vaccination is central for an effective and comprehensive control of the pandemic protecting against severe disease and drive

Maurizio Bonati

maurizio.bonati@marionegri.it

1 Department of Public Health, Istituto Di Ricerche Farmacologiche Mario Negri IRCCS, Milan, Italy herd immunity. This though scientific, social, and political questions (i.e., long-term safety, efficacy against variants, schedule, booster dose, effectiveness, surveillance, hesitancy, availability, access) remain to be resolved [5].

In this context, with the presence of effective vaccines, is it ethical to continue using placebo in SARS-CoV-2 vaccine trials? Scientific evidence indicates that, for clinical trials to have the best design, they should be controlled and, if possible, randomized and blinded. In testing the efficacy and safety of medicines, however, the control treatment in trials should allow the efficacy and safety of a new product to be compared with that of an established product of proven therapeutic value and not with the effect of a placebo. The ethical question concerning the design of new COVID-19 vaccine trials is therefore pertinent and current and would need a shared response. Currently, 32 vaccines are in largescale efficacy tests (phase 3) [3]. Fourteen of 37 COVID-19 vaccine phase 3 trials registered in Clinical Trial.gov are active and recruiting people to test a vaccine against placebo [6]. Redesigning ongoing trials to include an effective vaccine as the active comparator is difficult and not, according to some, necessary, even if participants should be appropriately informed also of the possibility of leaving the trial and obtaining an effective vaccine outside the research study [7].

Once clinical equipoise is resolved, the use of placebo is unjust [8]. In light of the available evidence and the approvals given, the disquisition between participants and not patients, and between researchers and clinicians, or, more in general, the social value contribution in participating in trials concerning preventive measures becomes less pertinent in supporting the use of placebo in the new phase 3 COVID-19 vaccine trials [7, 9-12].

However, all this seems to be a matter of reflection only for a part of the world where access to vaccination is guaranteed and the majority of the population is vaccinated: the condition of high-income countries. Unfortunately, only $1.2 \%$ of the global vaccine supply has been received by low-income countries and just $14 \%$ by lower-middle-income countries, which account for nearly $40 \%$ of the world's population [13]. Sharing technology and vaccine doses should be 
the challenge to address global vaccine inequity and end the COVID-19 pandemic [14], also in agreement with the article 15 of UNESCO's Universal Declaration on Bioethics and Human Rights that addresses benefit-sharing, "in particular with developing countries" [15]. An equal opportunity to receive the vaccine for people leaving in lower-middleincome countries cannot therefore be represented by being able to participate in placebo-vaccine trials [16]. This is not an action of solidarity or in support of the universal concept of dignity [17]. Furthermore, the duration of the trial is limited in time and involves a small minority of a population. So of little impact when the goal is the mass vaccination coverage. Other hypotheses suggested such as the one that the producers and national policymakers, once the trial has been completed with positive results, guarantee the access, and availability of the tested vaccine is at least illusory, it is unethical, and would help to increase global inequalities.

So, everywhere, clinical trials should contemplate placebo groups only for participants who would not be eligible for vaccination outside the trial (i.e., currently for children). Although an active comparison trial is likely to require more resources (i.e., larger sample size, longer duration), it is unethical to indiscriminately give participants a placebo when testing a vaccine candidate now that safe and effective COVID-19 vaccines are available and are currently being used, and when what we need to test is the added value, or at least an equivalent, of a new vaccine. This could be the challenge for a global control of COVID-19 pandemic.

\section{Declarations}

Conflict of interest The author declares no competing interests.

\section{References}

1. The United Nations (1948) Universal Declaration of Human Rights

2. International Health Conference (1946) Constitution of the World Health Organization. Off Rec Wld Hlth Org 2:100

3. Zimmer C, Corum J, Wee SL (2021) Coronavirus vaccine tracker. The New York Times. Updated August 4, 2021. https://www.nytimes.com/ interactive/2020/science/coronavirus-vaccine-tracker.html (accessed August 30, 2021)

4. World Health Organization (2021) https://apps.who.int/iris/ bitstream/handle/10665/337940/WHO-2019-nCoVPolicy_
Brief-EUD_placebo-controlled_vaccine_trials-2020.1-eng.pdf? sequence $=1 \&$ isAllowed $=y$ (accessed August 30, 2021)

5. Kim JH, Marks F, Clemens JD (2021) Looking beyond COVID-19 vaccine phase 3 trials. Nat Med 27:205-211. https://doi.org/10. 1038/s41591-021-01230-y

6. NIH U.S. National Library of Medicine (2021) ClinicalTrials. gov database. https://www.clinicaltrials.gov/ (accessed August 30, 2021)

7. Wendler D, Ochoa J, Millum J, Grady C, Taylor HA (2020) COVID-19 vaccine trial ethics once we have efficacious vaccines. Science 370(6522):1277-1279. https://doi.org/10.1126/science. abf5084

8. Friesen P, Caplan AL, Miller JE (2021) COVID-19 vaccine research and the trouble with clinical equipoise. Lancet 397(10274):576. https://doi.org/10.1016/S0140-6736(21)00198-7

9. Singh JA, Kochhar S, Wolff J (2021) WHO ACT-Accelerator Ethics \& Governance Working Group. Placebo use and unblinding in COVID-19 vaccine trials: recommendations of a WHO Expert Working Group. Nat Med 27(4): 569-570. https://doi.org/10. 1038/s41591-021-01299-5

10. Rid A, Lipsitch M, Miller FG (2021) The ethics of continuing placebo in SARS-CoV-2 vaccine trials. JAMA 325(3):219-220. https://doi.org/10.1001/jama.2020.25053

11. Sisa I, Noblecilla E, Orozco F (2021) Rationale to continue approving placebo-controlled COVID-19 vaccine trials in LMICs. Lancet 397(10277):878. https://doi.org/10.1016/S0140-6736(21) 00357-3

12. Krause PR, Fleming TR, Longini IM, Peto R, Beral V, Bhargava B, Cravioto A, Cramer JP, Ellenberg SS, Figueroa JP, Halloran E, Henao-Restrepo AM, Ryan MJ, Levine MM, Nason M, Nohynek HM, Plotkin S, Rees H, Singh JA, Swaminathan S (2021) WHO Ad Hoc Expert Group on the next steps for COVID-19 vaccine evaluation. Placebo-Controlled Trials of Covid-19 Vaccines - Why We Still Need Them. N Engl J Med 2021; 384(2):e2. https://doi. org/10.1056/NEJMp2033538.

13. Schellekens $P$ (2021) COVID-19 vaccine distribution relative to global needs. Pandem-ic. June 24, 2021. https://pandem-ic.com/ vaccination-by-region/ (accessed August 30, 2021)

14. Kavanagh MM, Gostin LO, Sunder M (2021) Sharing technology and vaccine doses to address global vaccine inequity and end the COVID-19 pandemic. JAMA 326(3):219-220. https://doi.org/10. 1001/jama.2021.10823

15. UNESCO (2021) Universal declaration on bioethics and human rights, October 2005. http://bit.ly/2ZFa1rB (accessed August 30, 2021)

16. Dal-Ré R, Bekker LG, Gluud C, Holm S, Jha V, Poland GA, Rosendaal FR, Schwarzer-Daum B, Sevene E, Tinto H, Voo TC, Sreeharan N (2021) Ongoing and future COVID-19 vaccine clinical trials: challenges and opportunities. Lancet Infect Dis May 18. https://doi.org/10.1016/S1473-3099(21)00263-2

17. Bruce L (2021) Global solidarity in COVID-19 vaccine distribution. BioLaw Journal 1:1-5. https://doi.org/10.15168/ 2284-4503-20211

Publisher's Note Springer Nature remains neutral with regard to jurisdictional claims in published maps and institutional affiliations. 